\title{
Mineralogy and Cultural Heritage
}

\author{
Gilberto Artioli
}

\begin{abstract}
In recent years there has been an escalation in the number of mineralogical studies involving cultural heritage materials. A number of factors have contributed to this exponential growth, including the shrinking budgets in traditional research fields, which forced the expansion of applications of mineralogical methods to novel research areas. Mineralogy as a discipline is traditionally connected to geology, petrology, and geochemistry, although it also has the strong tendency to embody the methods and techniques of modern crystallography and advanced materials science. Arguably, this makes it ideally suited and well equipped to meet the demanding challenges posed by archaeometric analysis and conservation problems. A few case studies linking mineralogy and archaeometry are discussed.
\end{abstract}

Keywords: Archaeometry $\cdot$ Conservation $\cdot$ Cultural heritage $\cdot$ Mineralogy

\section{Introduction}

Mineralogy as a natural science played a major role in the conceptual foundation of modern geology and Earth sciences in general, $\left.{ }^{1}\right]$ especially in the early days of mineralogical crystallography during the 16th and the 17th centuries. ${ }^{[2,3]}$ From the academic point of view mineralogy and crystallography are traditionally confined to Earth Sciences in the educational curricula, even though by definition they examine the very nature of crystalline solids making them in fact interdisciplinary sciences, at the intersection of sciences such as physics, chemistry, or materials science. Mineralogy therefore may well form a strong foundation for scientists working with cultural heritage materials, that is with materials that have been transformed through human activity.

Modern archaeometry and conservation sciences ${ }^{[4]}$ present demanding problems derived from the complexity of the chemical systems analyzed; from the

\footnotetext{
${ }^{\star}$ Correspondence: Prof. G. Artioli

Università di Padova

Dipartimento di Geoscienze

Via Giotto 1

I-35137 Padova

Tel.: +39049827 2037

Fax: + 390498272010

E-mail: gilberto.artioli@unipd.it
}

varying kinetics of the chemico-physical processes imposed on the cultural heritage material through time, and from the frequently limited availability of material for the analysis. Mineralogy, which naturally deals with complex mineral systems most often composed of a large number of chemical elements and several crystal-chemical phases, is technically and conceptually equipped to face the methodological and experimental challenges involved in the technical analysis of complex materials, and in the interpretation of the processes acting upon them. These factors, and the recent need to find new areas of application because of budgetary considerations for all scientific research, has driven the recent wave of mineralogical studies of cultural heritage materials. Here it is argued that, beyond the undisputed economical push, mineralogy at large is indeed the discipline possessing an adequate balance of the knowledge required to face cultural heritage problems.

\section{The Needs}

Technical analysis of cultural heritage materials is needed in order to place the heritage material into a well-interpreted time frame. Whenever we deal with archaeology, art history, conservation of museum collections, stabilization of architectural buildings, authentication, interpretation of urban or agricultural landscapes, or any other activity related to past human activities, inevitably the objects of our investigations (from single mineral particles to entire archaeological sites) must somehow be characterized and inserted in the proper frame involving the complete understanding of:

i) the physical, chemical, and mineralogical nature of the material, ii) its past history; i.e. its origin and the processes that acted upon it in the past, iii) its present condition; i.e. the kinetics of the processes presently acting on the material;

iv) its future history; i.e. projecting the active processes into the future.

In short, in cultural heritage studies we need to understand the present status of the material, the thermodynamics and the kinetics of the processes acting on it in order to retrieve information on its past and optimize the methods for its conservation for future generations.

All natural materials (inorganic: rocks and sediments; organic: wood, fibres, resins; and biominerals: bone, antler, shells, etc.) are inevitably transformed by man when shaped by tools. Even if the material is in a thermodynamically stable state, which is not necessarily the case for many materials even of geologic origin, during and after human use it is brought under different environmental conditions at least several times. This notably occurs during tool manufacturing and processing, usage in its lifetime, deposition in the archaeological settings, cleaning and/or conservation treatments, and finally during storage in museums and collections. All these events represent changes in the thermodynamic conditions of the material, and the material reacts accordingly. All technical analyses of cultural age materials are actually aimed at understanding the thermodynamics, the mechanisms, and/or the time-frame of the reactions involving them. A few examples: the thermoluminescence dating of ceramics measures the amount and rate of accumulation of electron traps in the mineral phases, to reveal the time elapsed since the last firing; the chemical analysis of a painting's stratigraphy sets the time sequence of the use of pigments by the artist for art historical purposes, or clarifies the nature and 
rate of pigment's alteration in time for restoration; the mineralogical and petrological analysis of metal smelting slags identifies the temperature and environmental conditions of the metallurgical processes used for metal reduction; the metallographic examination of metals helps understanding the manufacturing techniques (time-temperature-pressure path), their use as tools, and the post-burial alteration; and so on. Virtually all technical analyses yield information on the origin, manufacturing, diffusion, or dating of the investigated artefacts: they are inserted in the time-frame of human lifetime.

From the experimental point of view, modern mineralogy is routinely acquainted with the non-invasive or micro-invasive (i.e. microbeam) techniques often necessary to characterize small amounts of material or objects that cannot be sampled. It combines diffraction, spectroscopic, and imaging data to interpret complex polyphasic and composite materials, having structural and chemical disorder and defectivity. Mineralogy is naturally suited to characterize materials at different space and time scales.

All these factors combined support the extensive and appropriate use of mineralogy in the investigation of cultural heritage materials and problems.

\section{Examples}

Three case studies concerning different materials (glass, metals, mortar binders) are described in detail, in order to exemplify the important contribution that mineralogical knowledge may supply to archaeometric investigation.

\section{Glass: The Curious Case of Goethe's Blue Glass}

The recent investigation ${ }^{[5]}$ of the peculiar blue glass present in the altar decorations of several Baroque churches in Palermo (Fig. 1) was actually prompted by the sheer curiosity to understand the truth behind Goethe's personal accounts of the occasional glass production in the lime kilns surrounding the city, which he claimed to have witnessed during his travels in Italy. ${ }^{[6]}$ The onsite survey of several ancient lime kilns located south west of Palermo yield detailed observations of the flint-containing limestone formations that were quarried to extract the materials to be fired for lime production, as well as the recovery of a few raw blue glass fragments presumably produced in the kilns. Careful characterization of the samples by X-ray fluorescence (XRF), electron probe micro-analysis (EPMA), scanning electron microscopy (SEM), X-ray diffraction (XRD), and Mössbauer spec-

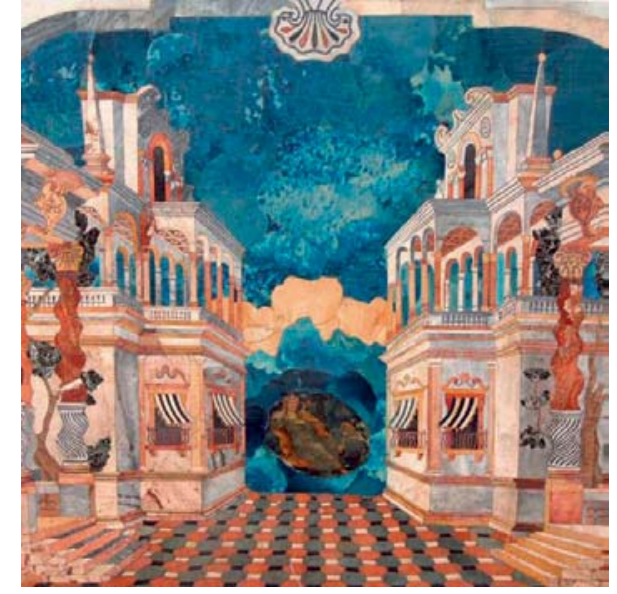

Fig. 1. Carved decorations of the altar in the Chapel of St. Benedetto, Church of the Immacolata Concezione al Capo, Palermo. The amazing 18th century blue glass composing the sky strikes among the other stones forming the picture, in the typical 'marmi mischi' style.

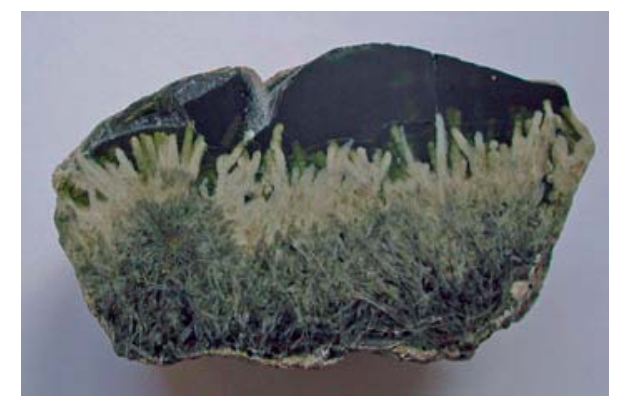

Fig. 2. Wollastonite crystals grown at the interface between the dark silica glass and the kiln-fired limestone.

troscopy, and subsequent comparison of the raw glass with the blue glass actually used in the altar decorations showed that i) all samples are composed of silica-lime based glass with an unusually high and variable amount of $\mathrm{K}^{+}$as network modifier cation, and ii) the blue colour is strangely produced by a very distorted octahedral environment of the $\mathrm{Fe}^{2+}$ cations. The analytical information, combined with the geological setting of the producing sites and with the available historical information on the mode of operation and on the fuel used in the kiln for firing, lets us conclude that indeed the blue glass employed for decoration in Palermo's churches was accidentally produced during local lime production, as reported by Goethe. The glass was the combined result of i) the fortuitous melting of the flint nodules present in the limestone (Fig. 2), whose melting point was substantially lowered by the activity of the $\mathrm{K}^{+}$cations released by the plants used as fuel, and ii) the highly reducing conditions experienced by the kiln charge, which determined the unusual valence and coordination state of the Fe cations. This peculiar material is the only reported blue glass used historically that is not coloured by $\mathrm{Cu}$ or $\mathrm{Co}$ ions.

This fascinating investigation required ample application of geological and mineralogical knowledge, the combined use of a number of analytical and spectroscopic techniques, the in-depth understanding of glass structure and chemistry, the reconstruction of ancient kiln firing techniques, and abundant historical information.

\section{Metals: The Puzzling Develop- ment of Alpine Prehistoric Copper Production}

Metals have always played a major role in human society, whether they are used for tools, status symbol, warfare, art, or exchange goods..$^{[7,8]}$ Topics of extreme interest for archaeologists, historians, art critics, museum curators, and many others working in cultural heritage ${ }^{[9]}$ include the discovery of metals, extraction technology, metallurgical processes, and their societal values, use for trade and exchange, physical properties, and their behaviour during alteration.

There are still many unanswered questions concerning the rise and development of copper mining and metallurgy in the Alpine area from the end of the Neolithic (approx. in the 5th millennium BC) to the end of the Bronze Age (approx. the beginning of the 1st millennium BC). The most basic question is: when and how were the ore resources in the Alps exploited for copper extraction? Our knowledge before the Iron Age is very fragmentary and we are confronted for example with mines showing early exploitation but little or no evidence of reduction slags (i.e. Libiola and Monte Loreto, Ligurian Alps, Italy; Saint Véran, Queyras, France), or with several smelting sites where a substantial amount of slags have been found, but they show no straightforward connection with the ore deposits (i.e. Luserna, Trentino; Renon, Alto Adige). Furthermore the geochemical and minerogenetic significance of many tracers used to link the metal objects to the smelting and extraction sites are a subject of debate. One further paradox is that there was abundant metal circulating since at least the 4th millennium $\mathrm{BC}$, as exemplified by the Iceman copper axe (approx. $3200 \mathrm{BC})^{[10]}$ and a number of coeval artefacts, but there is no clear evidence of large scale mining or smelting until half a millennium later. The only earlier recognized site is smallscale metallurgical activity confined to the Brixlegg site, in Tyrol.[11] Several sites with Chalcolithic slags are known in the Eastern Alps, ${ }^{[12,13]}$ although they mostly date to the mid 3rd century BC or later. They apparently indicate a sizeable mass copper production only towards the latter part of the Alpine Copper Age. 

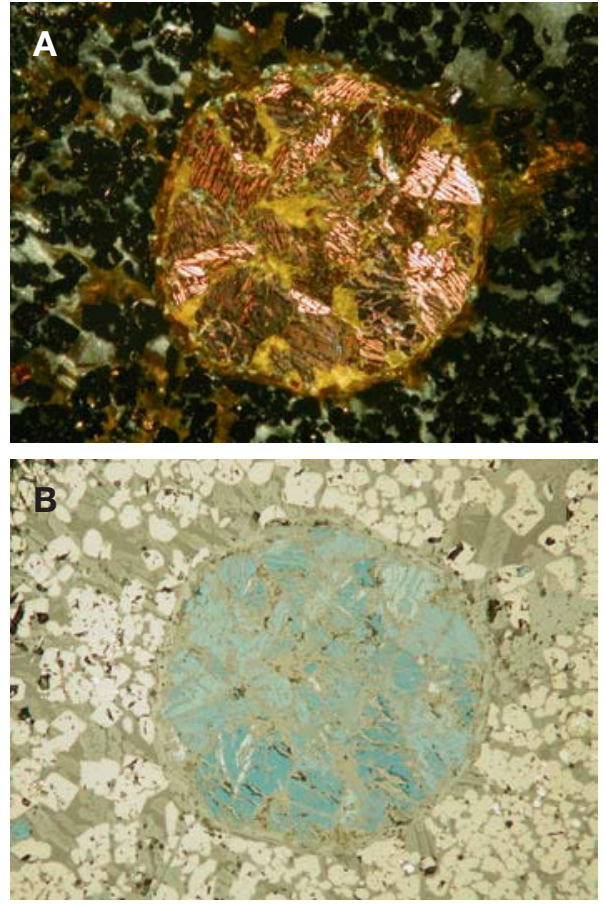

Fig. 3. Optical micrographs of a Chalcolithic copper smelting slag from Brixen, Alto Adige (A) plane-polarized reflected light, (B) crossedpolarized reflected light. The prill is composed by heavily reacted sulphide lamellae. The background mass is mainly composed of magnetite, olivine, and fayalitic glass.

In the last few years a long-term project focused on Alpine copper metallurgy was launched ${ }^{[14]}$ in order to investigate in detail the relationship between ores, slags, and metal. The core of the project is the development of an extensive database of Alpine copper mines containing mineralogical, petrological, chemical, isotopic, and genetic information on the ore deposits. ${ }^{[15]}$ Solid minerogenetic interpretation of the deposits and advanced statistical analysis of the ore chemical and isotopic data is the basis to understand the applicability of the measured geochemical tracers $(\mathrm{Pb}$ and $\mathrm{Cu}$ isotopic ratios, nearly 60 minor and trace elements, including REE elements) to metallurgical processes, including slagging and reduction smelting.

The discriminant analysis developed on the copper ore database was tested on the well-characterized area of Agordo, Alpi Bellunesi, Veneto, whose Valle Imperina copper mine was the principal source of copper for the Republic of Venice. The Agordo case study indicates that the developed discriminant models can be applied to the smelting slags (Fig. 3) and to the unalloyed raw copper extracted from the ores.

Recent applications of the models based on the database of geochemical tracers have met some success in i) firmly locating in the Monte Fondoli area (Pfunderer Bergwerk, Chiusa, Alto Adige) the source of the copper ores used for all known Chalcolithic smelting slags in the Brixen area (Millan, Gudon, Circonvallazione Ovest), and ii) identifying the source of the ores used for the production of the Late Bronze Age objects found in the Monte Cavanero hoard (Chiusa di Pesio, Cuneo, Western Alps).[16]

Once again, very intense and long-term multidisciplinary collaboration between mineralogists, geologists, archaeologists, and analytical chemists is the key to start disentangling rather complicated archaeometallurgical issues. On a slightly different side, mineralogical crystallography was also pivotal in intersecting competences as diverse as neutron diffraction, metallography, ancient copper metallurgy, and crystallographic texture analysis in order to promote the latter as a novel tool for the non-invasive metallographic interpretation of the manufacturing of metal objects. ${ }^{[17]}$

\section{Mortar Binders: Is each Mortar Different?}

At first sight, post-Roman mortars used through the Middle Ages are very simple, uninteresting materials produced with low technological processes: they are often composed by low quality lime (frequently loaded with clay or other mineralogical impurities), irregularly sized inert materials of different nature (mostly calcitic or dolomitic carbonates), and they do not show sign of pozzolanic reactions. They indeed seem to reflect the loss of the Roman technical abilities standardized by the Vitruvian reports, ${ }^{[18]}$ or at least they reflect the very local production following the fall of the Roman empire.

By checking the amount of information that can be recovered by the mineralogical analysis of Medieval mortars, a systematic investigation of the materials used in the different phases of construction of the Sachuidic castle, Friuli, Italy, ${ }^{[19]}$ was recently carried out. The castle (Fig. 4) was inhabited approximately in the 13th and 14th

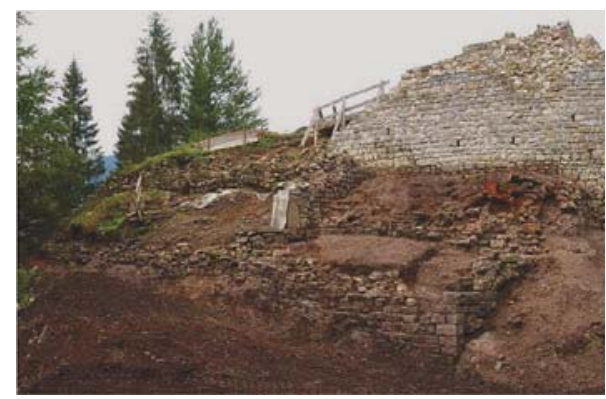

Fig. 4. The Medieval Sachuidic castle, Friuli, Italy, before restoration. The cluster analysis of the XRPD spectra of the mortars (Fig. 6) allows the detailed interpretation of the different building stages throughout the history of the site (Fig. 7). centuries AD, and in the last part of its history was the location of a clandestine mint.

The archaeometric analysis of the mortars focused on very precise questions: Can the different building phases be distinguished and confirmed by the analytical data? Are the quality and physical properties of the mortar related to the architectural role of the sampled structures?

Conventional optical microscopic analysis, also followed by partial digital image processing, supplied an overview of the mineralogy and the texture of the materials (Fig. 5), though it could not identify parameters useful for the unambiguous discrimination of all the materials. Only phase $2 \mathrm{a}$ can be easily distinguished on the basis of optical microscopy because of the presence of volcanic glass fragments in the mixture.

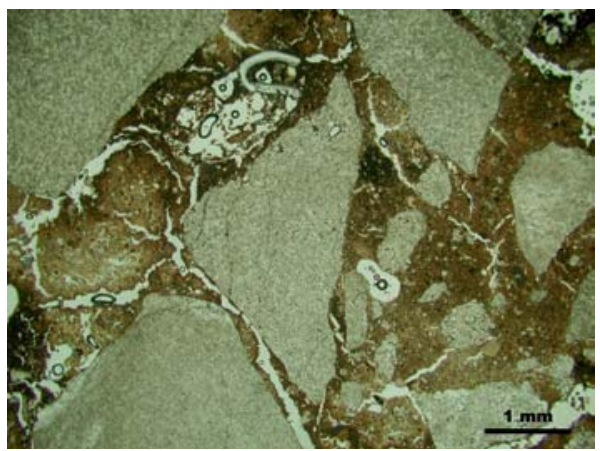

Fig. 5. Optical micrograph of the thin section of a mortar sample from the castle main wall. The inert clasts are composed of dolomite, and the rather impure binding matrix shows abundant cracks and the presence of calcite nodules related to the carbonation of the original portlandite lumps.

The investigation thus proceeded to the multivariate statistical analysis of the quantitative evaluation of the phases from XRPD. In this case simple principal component discrimination (Fig. 6) can readily separate the samples into four groups corresponding unambiguously to the main construction phases of the castle site. Not only the building stages are recognized, but also a few remaining doubts are resolved, such as the puzzling central section of the earliest building phase (phase 4, Fig. 7), which is confirmed to be a reconstruction carried out in the successive phase 3. Furthermore, the mortars pertaining to phase $2 \mathrm{a}$, which involved the later building of a massive reinforcement for the main castle tower are found to be of better quality with respect to the other binders. The higher mechanical resistance was obtained by mixing a small amount of local hyaloclastite glass that produced a sort of mild pozzolanic reaction at the binder-glass interface. ${ }^{[20]}$

The interesting results obtained on mortars show the ability of mineralogical investigation to aid in the detailed charac- 


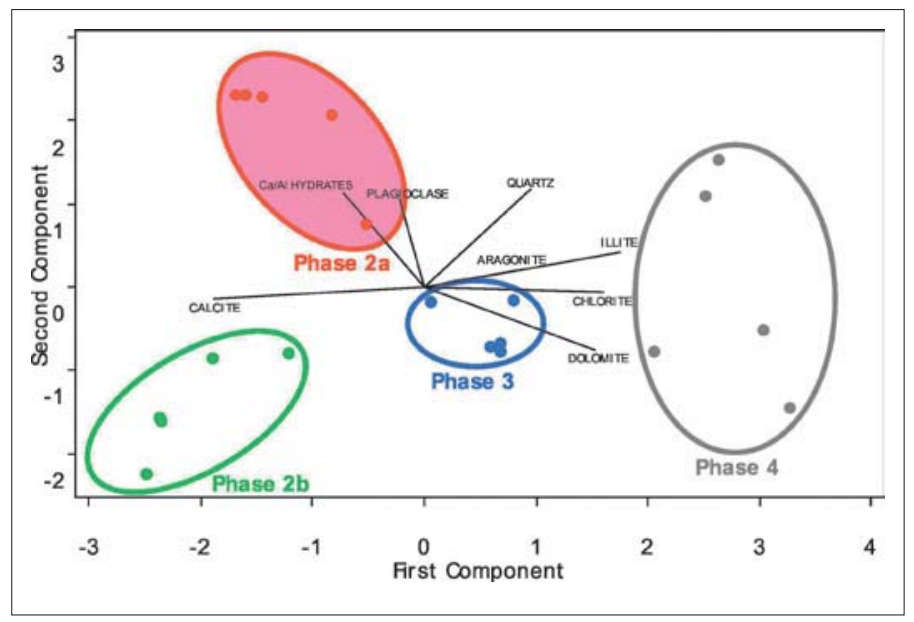

Fig. 6. Multivariate analysis performed on the XRPD spectra of the mortars sampled on all the construction phases of the Medieval Sachuidic castle. The colour code of the samples refers to the architectural building stages (Fig. 7).

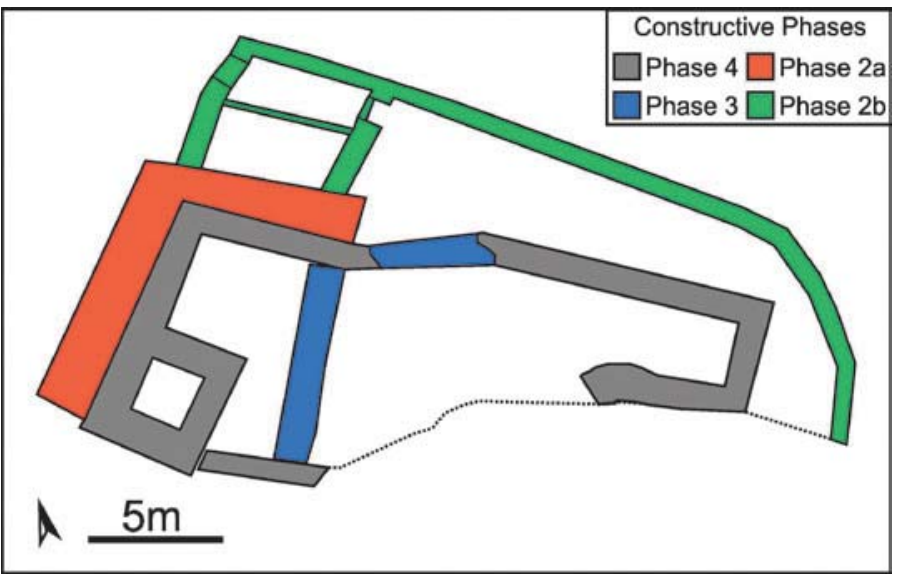

Fig. 7. The different construction stages of the Sachuidic castle (Fig. 4) as interpreted from the architectural survey and the analytical data of the mortars.

terization and contextualization of fairly complex materials.

\section{The Future}

The background information and the example studies discussed above point to mineralogy as a natural candidate discipline in the curriculum of every scientist dealing with cultural heritage materials. Knowledge of a vast array of analytical techniques, ${ }^{[4]}$ the rigorous perception of natural materials and processes in a wide geological context, and a good understanding of physico-chemical systems and processes are to be considered the fundamental background for the archaeometric and conservation-related investigations.

This established, it should be said that at present many truly interdisciplinary fields of investigation are facing serious economic and cultural problems, because of the general attitude to de-emphasize basic research and to reduce investments in areas considered unattractive for economic growth (i.e. the dominating 'nano-bio' attitude). Therefore in a period of shrinking budgets for cultural, academic, and scientific activities many disciplines are understandably striving to survive. While curiosity and cross-disciplinary openness ought to be the rule in science, all basic and applied sciences will inevitably suffer from the spreading attitude for hyper-specialization and from the rapidly degrading general level of higher education. This is in sharp contrast to the specific needs of cultural heritage investigations, requiring very high standards of competence, ingenuity, and a great deal of cross-disciplinary activity. Academia may well supply competence and ingenuity, but clearly a entirely different degree of cultural awareness is needed by economical and political managements. ${ }^{[21]}$

\section{Acknowledgements}

Giuseppe Montana, Filomena Gallo, and Michele Secco kindly provided photographs and/or graphic art. An anonymous reviewer greatly helped in cleaning the English style.

Received: June 6, 2010

[1] R. Laudan, 'From mineralogy to geology: the foundations of a science, 1650-1830', University of Chicago Press, Chicago, 1987.

[2] 'Historical Atlas of Crystallography', Ed. J. Lima-de-Faria, Kluwer Academic Publishers, Dordrecht/Boston/London, 1990.

[3] C. J. Schneer, Eur. J. Mineral. 1995, 7, 721.

[4] G. Artioli, 'Scientific Methods and the Cultural Heritage. An introduction to the application of materials science to archaeometry and conservation science', Oxford University Press, Oxford, 2010.
[5] G. Artioli, C. Nicola, G. Montana, I. Angelini, L. Nodari, U. Russo, Archaeometry 2009, 51, 197.

[6] J. W. Goethe, 'Italienische Reise', Herausgegeben und kommentiert von Herbert von Einem, Deutscher Taschenbuch Verlag, München, 1981.

[7] R. F. Tylecote, 'A history of metallurgy', The Metals Society, London, 1976.

[8] J. Diamond, 'Guns, germs, and steel. The fates of human societies', W. W. Norton \& Company, New York, 1999.

[9] T. Rehren, E. Pernicka, Archaeometry 2008, 50, 232.

[10] A. Fleckinger, 'Ötzi, the iceman. The full facts at a glance', Folio Verlag, Bolzano, 2007.

[11] B. Höppner, M. Bartelheim, M. Huijsmans, R. Krauss, K.-P. Martinek, E. Pernicka, R. Schwab, Archaeometry 2005, 47, 293.

[12] G. Artioli, I. Angelini, E. Burger, D. Bourgarit, in Proc. 2nd Int. Conference 'Archaeometallurgy in Europe 2007', Selected Papers Volume, AIM, Milano, 2009, pp. 12-20.

[13] F. Colpani, I. Angelini, G. Artioli, U. Tecchiati, in Proc. ISA 2006, 36th Intern. Symposium on Archaeometry, Eds. J. F. Moreau, R. Auger, J. Chabot, A. Herzog, Cahiers d'archéologie du CELAT, n. 25, Série Archéometrie, n. 7. CELAT, Université Laval, Quebec, 2009, pp. 367-374.

[14] AAcP, Alpine Archaeocopper Project: $w w w$. geoscienze.unipd.it/ artioli/aacp/welcome.html

[15] G. Artioli, B. Baumgarten, M. Marelli, B. Giussani, S. Recchia, P. Nimis, I. Giunti, I. Angelini, P. Omenetto, Geo. Alp 2008, 5, 139.

[16] G. Artioli, I. Angelini, I. Giunti, P. Omenetto, I. Villa, in 'Il ripostiglio del Monte Cavanero di Chiusa di Pesio (Cuneo)', Ed. M. Venturino Gambari, LineLab. Edizioni, Alessandria, 2009, pp. 167-178.

[17] G. Artioli, Appl. Physics A 2007, 89, 899.

[18] Marcus Vitruvius Pollio, 'De Architectura', Engl. transl., Eds. I. D. Rowland, T. H. Howe, 'Vitruvius: Ten Books on Architecture', Cambridge University Press, Cambridge, 1999.

[19] S. Gelichi, F. Piuzzi, A. Cianciosi, 'Sachuidic presso Forni Superiore. Ricerche archeologiche in un castello della Carnia', All'Insegna del Giglio, Firenze, 2008.

[20] M. Secco, G. Artioli, C. Mazzoli, S. Gelichi, A. Cianciosi, F. Piuzzi, ISA2010, 38th International Symposium on Archaeometry, Tampa, Florida, 10-14 May 2010. Abst Vol. Poster N. 67, pp. 115-116.

[21] M. Maggetti, 'Archaeometry: Quo vadis?', Geol. Soc. London, Special Publications 2006, 257, 1. 